\title{
ROLE OF FRUITS ON PUBLIC HEALTH
}

\author{
M Asaduzzaman ${ }^{1}$ M A Islam² and M M Islam ${ }^{3}$
}

\begin{abstract}
An investigation was carried out on the role of fruits on public health. Amount of nutrition value on different fruits of Bangladesh also examined. Fruits are not only good source of vitamins and minerals but also highly nutritive with anti carcinogenic value. The role of sufficient intake of fruits can prevent many life threatening diseases of human beings like diabetics, blood pressure, heart diseases and cancer. Altogether 39 fruits, the highest water portion $96.6 \mathrm{~g}$ was found in black berry and Jamun, and the lowest $4.3 \mathrm{~g}$ were found in coconut. The highest total minerals $1.7 \mathrm{~g}$ was measured in date palm and the lowest $0.1 \mathrm{~g}$ was found in orange, black berry and Jamun. The maximum fiber $6.6 \mathrm{mg}$ was found in coconut and the lowest $0.2 \mathrm{~g}$ was found in jackfruit and water melon. The highest Calorie $662 \mathrm{Kcal}$ was found in coconut and the lowest $11 \mathrm{Kcal}$ was measured in black berry and Jamun. The highest protein $3.5 \mathrm{~g}$ was found in elephant's foot apple and the lowest $0.2 \mathrm{~g}$ was found in water melon. The highest fat $62.3 \mathrm{~g}$ was found in coconut and the lowest $0.1 \mathrm{~g}$ was found in jackfruit, ber, elephant's foot apple, orange, Bullock's heart/Custard apple, Hogplum, Olive, Aonla, River ebony and Water chestnut. The highest Carbohydrate $33.8 \mathrm{~g}$ was found in date palm and the lowest $1.4 \mathrm{~g}$ was found in black berry and Jamun. The highest $90 \mathrm{mg}$ was found in Lime and the lowest $0.01 \mathrm{~g}$ was found in River ebony. The highest amount of Fe $7.9 \mathrm{mg}$ was found in water melon and the lowest $0.2 \mathrm{mg}$ was found in Pummelo. The highest amount of Carotene $8300 \mu \mathrm{g}$ was found in mango and the lowest $0 \mu \mathrm{g}$ was found in litchi, ber, elephant's foot apple, orange, lemon, Bullock's heart/Custard apple, coconut, banana, Aonla and water chestnut. The highest amount of vitamin B-1 $0.8 \mathrm{mg}$ was found in elephant's foot apple and the lowest $0.01 \mathrm{mg}$ was found in Wax apple, tamarind and Rose apple. The highest amount of vitamin B-2 $0.19 \mathrm{mg}$ was found in Burmese grape and the lowest B-2 $0.01 \mathrm{mg}$ was found in orange, coconut and olive. The highest amount of vitamin C $463 \mathrm{mg}$ was found in Aonla and Stargareberry, and the lowest $1 \mathrm{mg}$ was found in coconut and water melon.
\end{abstract}

Key words: Fruits, Public health.

\section{INTRODUCTION}

Fruits are not only good source of vitamins and minerals but also highly nutritive with anti carcinogenic value. The role of sufficient intake of fruits can prevent many life threatening diseases of human beings like diabetics, blood pressure, heart diseases and cancer. Fruit is an important component of a healthy diet and, if consumed daily in sufficient amounts, could help prevent major diseases such as noncommunicable diseases (NCDs), especially cardiovascular diseases (CVDs), cancers, obesity and 2 diabetes mellitus. According to world health report 2002, low fruit intake is estimated to cause about $31 \%$ of ischemic heart disease and $11 \%$ of stroke worldwide. Overall it is estimated that up to 2.7 million lives could potentially be saved each year if fruit and vegetables consumption was sufficiently increased. Recommendations in this direction tend to complement and reinforce other valid messages based on the long-known health benefits of consuming fruit as dietary sources of fiber, proteins and protective micronutrients. The recent joint FAO/WHO expert consultation on diet, nutrition and the prevention of chronic diseases, recommended the intake of a minimum of $400 \mathrm{~g}$ of fruit and vegetables per day for the prevention of chronic diseases such as heart disease, cancer, diabetes and obesity, as well as for the prevention and alleviation of several micronutrient deficiencies, especially in less developed countries. The recommendation thus adds to the already strong case for the health benefits to be gained from the

\footnotetext{
${ }^{1}$ Executive Director, Bangladesh Science Foundation, Uttara Model Town, Dhaka -1213, Bangladesh

${ }^{2}$ CO, AFMSD, Dhaka Cantonment, Dhaka and Research Fellow, State University of Bangladesh, Dhaka.

${ }^{3}$ Senior Scientific Officer, Plant Pathology Division, BARI, Gazipur
} 
consumption of fruit and paves the way for concrete action advocating increased consumption of these commodities.

WHO has responded to the global rise in NCDs by giving increasing attention to their prevention and control, most recently through the Global Strategy on Diet, Physical activity and health endorsed at the Fifty seven World Health Assembly on 22 May 2004. Within the framework of this Global Strategy, WHO aims to actively promote an increase in fruit intake worldwide. To reach this goal, WHO and FAO have formed a partnership around the theme of fruit for health.

WHO and FAO announced their joint effort at the Third Global Forum on NCD Prevention and Control held in Rio de Janeiro, Brazil, in November 2003, emphasizing that worlwide awareness of the health benefits consumption needs to be increased. In addition, accelerated national initiatives are required to produce and efficiently market more affordable horticultural products, while ensuring that they are safe and that fewer losses occur along the post-harvest handling chain.

WHO and FAO held their first joint workshop- Fruit and Vegetables for Health - at the WHO Center for Health Development in Kobe, Japan, on 1-3 September 2004. Participants included nutrition, health and agricultural scientists, representatives from ministries of health and agriculture, advisers on nutrition from WHO Regional Officers, experts from the World. Considering the above circumstances, the present investigation was conducted to see the role of fruits on public health in Bangladesh.

\section{MATERIALS AND METHODS}

Secondary data was collected from Agriculture Information Center (AIS), Khamarbari, Dhaka; Bangladesh Academy of Science (BAS) Library, Bangladesh Agricultural Research Institute (BARI) Library, Bangladesh Agricultural Agricultural University (BAU) Library, FAO/WHO reports and internet to write this paper.

\section{RESULTS AND DISCUSSION}

Amount of water portion (g), total minerals(g), fiber (mg), calorie (KCal), protein (g), fat (g), carbohydrate (g), Ca (mg), Fe (m g), Carotene ( $\mu \mathrm{g})$, Vitamin B-1 (mg), Vitamin B-2 (mg) and Vitamin C (mg) were 78.6, 0.4, 0.7, 90, 1.0, 0.7, 20.0, 16, 1.3, 8300, 0.10, 0.07 and 41respecrively in mango; Amount of water portion (g), total minerals(g), fiber (mg), calorie (KCal), protein (g), fat (g), carbohydrate (g), Ca (mg), Fe (m g), Carotene ( $\mu \mathrm{g})$, Vitamin B-1 (mg), Vitamin B-2 (mg) and Vitamin C (mg) were 88.0, 1.1, 0.2, 48, 1.8, 0.1, 9.9, 20, 0.5, 4700, 0.11, 0.15 and 21in jackfruit; Amount of water portion (g), total minerals(g), fiber (mg), calorie (KCal), protein (g), fat (g), carbohydrate (g), Ca (mg), Fe (m g), Carotene ( $\mu \mathrm{g})$, Vitamin B-1 (mg), Vitamin B-2 (mg) and Vitamin C (mg) were 84.1, 0.5, 0.5, 61, 1.1, 0.2, 13.6, 10, 0.7, 0, 0.02, 0.06 and 31in litchi. Amount of water portion (g), total minerals(g), fiber (mg), calorie (KCal), protein (g), fat (g), carbohydrate (g), Ca (mg), Fe (m g), Carotene ( $\mu \mathrm{g})$, Vitamin B-1 (mg), Vitamin B-2 (mg) and Vitamin C (mg) were 81.7, 0.7, 5.2, 51, 0.9, 0.3, 11.2, 10, 1.4, 100, 0.21, 0.09 and 210 in guava; Amount of water portion (g), total minerals(g), fiber (mg), calorie (KCal), protein (g), fat (g), carbohydrate (g), Ca (mg), Fe (m g), Carotene ( $\mu \mathrm{g})$, Vitamin B-1 (mg), Vitamin B-2 (mg) and Vitamin C (mg) were 84.6, 0.7, 1.3, 59, 1.5, 1.0, 10.9, 90, 0.3, 15, 0.02, 0.03 and 63 in lime; Amount of water portion (g), total minerals(g), fiber (mg), calorie (KCal), protein (g), fat (g), carbohydrate (g), Ca (mg), Fe (m g), Carotene ( $\mu \mathrm{g})$, Vitamin B-1 (mg), Vitamin B-2 (mg) and Vitamin C (mg) were 73.2, 1.0, 104, 2.9, 0.1, 23.8, 11, -, 0, 0.02, 0.05 and 51in ber; Amount of water portion (g), total minerals(g), fiber (mg), calorie (KCal), protein (g), fat (g), carbohydrate (g), Ca (mg), Fe (m g), Carotene ( $\mu \mathrm{g})$, Vitamin B-1 (mg), Vitamin B2 (mg) and Vitamin C (mg) were 77.5, 0.9, 2.9, 87, 2.6, 0.2, 18.8, 38, 0.6, -, 0.03, 0.02 and 9 in bel; Amount of water portion (g), total minerals(g), fiber (mg), calorie (KCal), protein (g), fat (g), carbohydrate (g), Ca (mg), Fe (m g), Carotene ( $\mu \mathrm{g})$, Vitamin B-1 (mg), Vitamin B-2 (mg) and Vitamin C (mg) were 85.6, 2.2, 5.0, 49, 3.5, 0.1, 8.6, 59, 0.6, 0, 0.80, 0.03 and 13 in elephant's foot apple; Amount of water portion (g), total minerals(g), fiber (mg), calorie (KCal), protein (g), fat (g), carbohydrate (g), Ca (mg), Fe (m g), Carotene ( $\mu \mathrm{g})$, Vitamin B-1 (mg), Vitamin B-2 (mg) and Vitamin C (mg) were 90.3, 0.3, -, 38, 0.5, 0.3, 8.5, 37, 0.2, 120, 0.06, 0.04 and 105 in pommelo; 
Amount of water portion (g), total minerals(g), fiber (mg), calorie (KCal), protein (g), fat (g), carbohydrate (g), Ca (mg), Fe (m g), Carotene ( $\mu \mathrm{g})$, Vitamin B-1 (mg), Vitamin B-2 (mg) and Vitamin C (mg) were 88.4, 0.6, 1.7, 47, 0.3, 0.7, 10.0, 40, 2.3, -, 0.03 and 47 in lemon; Amount of water portion (g), total minerals(g), fiber (mg), calorie (KCal), protein (g), fat (g), carbohydrate (g), Ca (mg), Fe (m g), Carotene ( $\mu \mathrm{g})$, Vitamin B-1 (mg), Vitamin B-2 (mg) and Vitamin C (mg) were 89.4, 0.1, 0.3, 43, 0.7, 0.1, 9.7, 22, 0.3, -, 0.04, 0.01 and 40 in orange; Amount of water portion (g), total minerals(g), fiber (mg), calorie (KCal), protein (g), fat (g), carbohydrate (g), Ca (mg), Fe (m g), Carotene $(\mu \mathrm{g})$, Vitamin B-1 (mg), Vitamin B-2 (mg) and Vitamin C (mg) were 96.6, 0.1, 3.8, 11, 1.0, 0.8, 1.4, 22, 4.3, 120, 0.01, 0.024 and 60in blackberry; Amount of water portion (g), total minerals(g), fiber (mg), calorie (KCal), protein (g), fat (g), carbohydrate (g), Ca (mg), Fe (m g), Carotene ( $\mu \mathrm{g})$, Vitamin B-1 (mg), Vitamin B-2 (mg) and Vitamin C (mg) were 76.7, 0.9, 3.1, 90, 1.8, 0.1, 20.6, 17, 1.5, 0, 0.07, 0.14 and 38 in Bullock's heart/Custard apple; Amount of water portion (g), total minerals(g), fiber (mg), calorie (KCal), protein (g), fat (g), carbohydrate (g), Ca (mg), Fe (m g), Carotene ( $\mu \mathrm{g})$, Vitamin B-1 (mg), Vitamin B-2 (mg) and Vitamin C (mg) were 88.6, 0.4, 1.0, 50, 0.5, 1.0, 9.5, 11, 1.2, -, 0.12, 0.04 and 61 in carambola;

Amount of water portion (g), total minerals(g), fiber (mg), calorie (KCal), protein (g), fat (g), carbohydrate (g), Ca (mg), Fe (m g), Carotene ( $\mu \mathrm{g})$, Vitamin B-1 (mg), Vitamin B-2 (mg) and Vitamin C (mg) were 80.9, 0.6, 5.1, 74, 1.6, -, 16.9, 21, 0.3, -, 0.02, - and 26 in pomegranate;

Amount of water portion (g), total minerals(g), fiber (mg), calorie (KCal), protein (g), fat (g), carbohydrate (g), Ca (mg), Fe (m g), Carotene ( $\mu \mathrm{g})$, Vitamin B-1 (mg), Vitamin B-2 (mg) and Vitamin C (mg) were 83.2, 0.6, 1.0, 66, 1.1, 0.1, 15, 55, 3.9, 800, 0.28, 0.04 and 92 in hogplum; Amount of water portion (g), total minerals(g), fiber (mg), calorie (KCal), protein (g), fat (g), carbohydrate (g), Ca (mg), Fe (m g), Carotene ( $\mu \mathrm{g})$, Vitamin B-1 (mg), Vitamin B-2 (mg) and Vitamin C (mg) were 89.1, 0.3, 1.2, 39, 0.7, 0.2, 8.5, 10, 0.5, 141, 0.01, 0.05 and 3 in wax apple; Amount of water portion (g), total minerals(g), fiber (mg), calorie (KCal), protein (g), fat (g), carbohydrate (g), Ca (mg), Fe (m g), Carotene ( $\mu \mathrm{g})$, Vitamin B-1 (mg), Vitamin B-2 (mg) and Vitamin C (mg) were 4.3, 1.6, 6.6, 662, 6.8, 62.3, 18.4, 40, 2.7, 0, 0.08, 0.01 and 1 in coconut; Amount of water portion (g), total minerals(g), fiber (mg), calorie (KCal), protein (g), fat (g), carbohydrate (g), Ca (mg), Fe (m g), Carotene ( $\mu \mathrm{g})$, Vitamin B-1 (mg), Vitamin B-2 (mg) and Vitamin C (mg) were 62.7, 0.9, 0.4, 109, 0.7, 0.8, 25.0, 13, 0.9, 0, 0.10, 0.05 and 28 in banana; Amount of water portion (g), total minerals(g), fiber (mg), calorie (KCal), protein (g), fat (g), carbohydrate (g), Ca (mg), Fe (m g), Carotene ( $\mu \mathrm{g})$, Vitamin B-1 (mg), Vitamin B-2 (mg) and Vitamin C (mg) were 88.4, 0.7, 0.8, 42, 1.9, 0.2, 8.3, 31, 0.5, 8100, 0.08, 0.03 and 57 in papaya; Amount of water portion (g), total minerals(g), fiber (mg), calorie (KCal), protein (g), fat (g), carbohydrate (g), Ca (mg), Fe (m g), Carotene ( $\mu \mathrm{g})$, Vitamin B-1 (mg), Vitamin B-2 (mg) and Vitamin C (mg) were 92.4, 0.2, -, 30, 0.9, 0.2, 6.2, 18, -, 1830, 0.11, 0.04 and 21 in pineapple; Amount of water portion (g), total minerals(g), fiber (mg), calorie (KCal), protein (g), fat (g), carbohydrate (g), Ca (mg), Fe (m g), Carotene ( $\mu \mathrm{g})$, Vitamin B-1 (mg), Vitamin B-2 (mg) and Vitamin C (mg) were 82.0, 0.7, 1.6, 70, 1.0, 0.2, 16.2, 22, 3.1, -, 0.03, 0.0 and 39 in olive; Amount of water portion (g), total minerals(g), fiber (mg), calorie (KCal), protein (g), fat (g), carbohydrate (g), Ca (mg), Fe (m g), Carotene ( $\mu \mathrm{g})$, Vitamin B-1 (mg), Vitamin B-2 (mg) and Vitamin C (mg) were 91.4, 0.7, 3.4, 19, 0.9, 0.1, 3.5, 34, 1.2, 0, 0.02, 0.08 and 463 in aonla; Amount of water portion (g), total minerals(g), fiber (mg), calorie (KCal), protein (g), fat (g), carbohydrate (g), Ca (mg), Fe (m g), Carotene $(\mu \mathrm{g})$, Vitamin B-1 (mg), Vitamin B-2 (mg) and Vitamin C (mg) were 83.6, 1.2, -, 62, 1.1, $0.1,13.9,24,-,-, 0.01,0.02$ and 6 in tamarind; Amount of water portion (g), total minerals(g), fiber (mg), calorie (KCal), protein (g), fat (g), carbohydrate (g), Ca (mg), Fe (m g), Carotene ( $\mu \mathrm{g})$, Vitamin B-1 (mg), Vitamin B-2 (mg) and Vitamin C (mg) were 77.5, 0.7, 0.5, 87, 0.7, 0.2, 20.7, 9, -, -, -, - and - in palmyara palm; Amount of water portion (g), total minerals(g), fiber (mg), calorie (KCal), protein (g), fat (g), carbohydrate (g), Ca (mg), Fe (m g), Carotene ( $\mu \mathrm{g})$, Vitamin B-1 (mg), Vitamin B-2 (mg) and Vitamin C (mg) were 59.2, 1.7, 3.7, 144, 1.2, 0.4, 33.8, 22, -, -, -, - and - in date palm; Amount of water portion (g), total minerals(g), fiber (mg), calorie (KCal), protein (g), fat (g), carbohydrate (g), Ca (mg), Fe (m g), Carotene ( $\mu \mathrm{g})$, Vitamin B-1 (mg), Vitamin B-2 (mg) and Vitamin C (mg) were 69.6, 0.8, 1.5, 133, 1.4, 0.1, 26.6, 58, -, -, -, - and - in riverebony; Amount of water portion (g), total minerals(g), fiber (mg), calorie (KCal), protein (g), fat (g), carbohydrate (g), Ca (mg), Fe (m g), Carotene ( $\mu \mathrm{g})$, Vitamin B-1 (mg), Vitamin B-2 (mg) and Vitamin C (mg) were 88.1, 0.6, 2.2, 37, 1.3, 0.2, 7.6, 80, 1.1, 162, 0.06, 0.05 and 5 in fig; Amount of water portion (g), total minerals(g), fiber 
(mg), calorie (KCal), protein (g), fat (g), carbohydrate (g), Ca (mg), Fe (m g), Carotene ( $\mu \mathrm{g})$, Vitamin B-1 (mg), Vitamin B-2 (mg) and Vitamin C (mg) were 84.9, 0.9, 0.6, 65, 2.5, 0.9, 11.7, 10, 0.8, 0, 0.18, 0.05 and 15 in water chestnut; Amount of water portion (g), total minerals(g), fiber (mg), calorie (KCal), protein (g), fat (g), carbohydrate (g), Ca (mg), Fe (m g), Carotene ( $\mu \mathrm{g})$, Vitamin B-1 (mg), Vitamin B-2 (mg) and Vitamin C (mg) were -, 0.9, -. 91, 1.42, 0.45, -, -, 0.3, -, 0.03, 0.19 and - in burmese grape; Amount of water portion (g), total minerals(g), fiber (mg), calorie (KCal), protein (g), fat (g), carbohydrate (g), Ca (mg), Fe (mg), Carotene ( $\mu \mathrm{g})$, Vitamin B-1 (mg), Vitamin B-2 (mg) and Vitamin C (mg) were -, 0.8, 59, 0.8, 0.2, 13.4, 16, -, -, -, - and - in Indian dellenia; Amount of water portion (g), total minerals(g), fiber (mg), calorie (KCal), protein (g), fat (g), carbohydrate (g), Ca (mg), Fe (mg), Carotene ( $\mu \mathrm{g})$, Vitamin B-1 (mg), Vitamin B-2 (mg) and Vitamin C (mg) were 84.9, $0.2,1.5,60,0.5,0.1,14.3,0.01,0.2,-,-,-$ - and - in velvety apple; Amount of water portion (g), total minerals(g), fiber (mg), calorie (KCal), protein (g), fat (g), carbohydrate (g), Ca (mg), Fe (m g), Carotene $(\mu \mathrm{g})$, Vitamin B-1 (mg), Vitamin B-2 (mg) and Vitamin C (mg) were -, 0.8, -, 66, 0.7, -, 13.3, 50, 0.5, -, 0.02, 0.15 and 135 in monkey jack. Amount of water portion (g), total minerals(g), fiber (mg), calorie (KCal), protein (g), fat (g), carbohydrate (g), Ca (mg), Fe (m g), Carotene ( $\mu \mathrm{g})$, Vitamin B-1 (mg), Vitamin B-2 (mg) and Vitamin C (mg) were 91.4, 0.7, 3.4, 19, 0.9, 0.1, 3.5, 34, 1.2, -, 0.02, 0.08 and 463 in stargareberry; Amount of water portion (g), total minerals(g), fiber (mg), calorie (KCal), protein (g), fat (g), carbohydrate (g), Ca (mg), Fe (m g), Carotene ( $\mu \mathrm{g})$, Vitamin B-1 (mg), Vitamin B-2 (mg) and Vitamin C (mg) were -, 0.5, -, 39, 0.7, 0.2, 23.0, 10, 0.5, 141, 0.01, 0.05 and 53 in rose apple; Amount of water portion (g), total minerals(g), fiber (mg), calorie (KCal), protein (g), fat (g), carbohydrate (g), Ca (mg), Fe (m g), Carotene ( $\mu \mathrm{g})$, Vitamin B-1 (mg), Vitamin B2 (mg) and Vitamin C (mg) were 96.6, 0.1, 3.8, 11, 1.0, 0.8, 1.4, 22, 4.3, 120, 0.09, 0.02 and 60 in jamun; Amount of water portion (g), total minerals(g), fiber (mg), calorie (KCal), protein (g), fat (g), carbohydrate (g), Ca (mg), Fe (m g), Carotene ( $\mu$ g), Vitamin B-1 (mg), Vitamin B-2 (mg) and Vitamin C (mg) were -, -, 0.64, -, 1.42, 0.45, -, -, -, -, -, - and - in longan; Amount of water portion (g), total minerals(g), fiber (mg), calorie (KCal), protein (g), fat (g), carbohydrate (g), Ca (mg), Fe (m g), Carotene $(\mu \mathrm{g})$, Vitamin B-1 (mg), Vitamin B-2 (mg) and Vitamin C (mg) were 78.7, 1.0, 0.7, -, 2.6, 0.4, 17.3, 11, 0.6 -, 0.09, 0.06 and - in plantain; Amount of water portion (g), total minerals(g), fiber (mg), calorie (KCal), protein (g), fat (g), carbohydrate (g), Ca (mg), Fe (m g), Carotene ( $\mathrm{gg})$, Vitamin B-1 (mg), Vitamin B-2 (mg) and Vitamin C (mg) were in water melon (Table 1).

Out of 39 fruits, the highest water $96.6 \mathrm{~g}$ was found in black berry and Jamun, and the lowest $4.3 \mathrm{~g}$ was found in coconut. The highest total minerals $1.7 \mathrm{~g}$ was measured in date palm and the lowest $0.1 \mathrm{~g}$ was found in orange, black berry and Jamun. The maximum fiber $6.6 \mathrm{mg}$ was found in coconut and the lowest $0.2 \mathrm{~g}$ was found jackfruit and water melon. The highest Calorie $662 \mathrm{Kcal}$ was found in coconut and the lowest $11 \mathrm{Kcal}$ was measured in black berry and Jamun. The highest protein $3.5 \mathrm{~g}$ was found in elephant's foot apple and the lowest $0.2 \mathrm{~g}$ was found in water melon. The highest fat $62.3 \mathrm{~g}$ was found in coconut and the lowest $0.1 \mathrm{~g}$ was found in jackfruit, ber, elephant's foot apple, orange, Bullock's heart/Custard apple, Hogplum, Olive, Aonla, River ebony, River ebony and Water chestnut. The highest Carbohydrate $33.8 \mathrm{~g}$ was found in date palm and the lowest $1.4 \mathrm{~g}$ was found in black berry and Jamun. The highest $90 \mathrm{mg}$ was found in Lime and the lowest $0.01 \mathrm{~g}$ was found in River ebony. The highest amount of Fe $7.9 \mathrm{mg}$ was found in water melon and the lowest $0.2 \mathrm{mg}$ was found in Pummelo. The highest amount of Carotene $8300 \mu \mathrm{g}$ was found in mango and the lowest $0 \mu \mathrm{g}$ was found in litchi, ber, elephant's foot apple, orange, lemon, Bullock's heart/Custard apple, coconut, banana, Aonla and water chestnut. The highest amount of vitamin B-1 $0.8 \mathrm{mg}$ was found in elephant's foot apple and the lowest $0.01 \mathrm{mg}$ was found in Wax apple, tamarind and Rose apple. The highest amount of vitamin V2 $0.19 \mathrm{mg}$ was found in Burmese grape and the lowest V2 $0.01 \mathrm{mg}$ was found in orange, coconut and olive. The highest amount of vitamin C $463 \mathrm{mg}$ was found in Aonla and Stargareberry, and the lowest $1 \mathrm{mg}$ was found in coconut and water melon.

The fruit has high nutritive value, and significantly contributes to the people of Bangladesh as a source of vitamins, minerals and calories, etc. The edible parts of ripe fruits contain high amount of vitamin A. It is estimated that around 30000 children become blind every year only due to vitamin A deficiency in Bangladesh. Vitamin B complex help convert food to energy. The minerals keep the body balance and iron which is present in blood helps movement to oxygen through the body. Increasing consumption of fruits carries a large public health potential. The available evidence is sufficient to justify public health and promotion aimed at a substantial increase in the consumption of fruits. 
Table 1. Nutrition value of different fruits in $100 \mathrm{~g}$ edible fruit.

\begin{tabular}{|c|c|c|c|c|c|c|c|c|c|c|c|c|c|}
\hline $\begin{array}{l}\text { Fruits } \\
\text { name }\end{array}$ & $\begin{array}{c}\text { Water } \\
\text { portion }\end{array}$ & $\begin{array}{c}\text { Total } \\
\text { minerals }\end{array}$ & $\begin{array}{l}\text { Fiber } \\
\text { (mg) }\end{array}$ & $\begin{array}{l}\text { Calorie } \\
\text { (KCal) }\end{array}$ & $\begin{array}{l}\text { Protein } \\
\text { (g) }\end{array}$ & $\begin{array}{l}\text { Fat } \\
\text { (g) }\end{array}$ & $\begin{array}{l}\text { Carbohy } \\
\text { drate (g) }\end{array}$ & Ca (mg) & $\begin{array}{c}\text { Fe } \\
(\mathrm{m} \mathrm{g})\end{array}$ & $\begin{array}{c}\text { Caro-tene } \\
(\mu g)\end{array}$ & $\begin{array}{c}\text { Vita. B-1 } \\
\text { (mg) }\end{array}$ & $\begin{array}{c}\text { Vita.B-2 } \\
\text { (mg) }\end{array}$ & $\begin{array}{c}\text { Vita.C } \\
\text { (mg) }\end{array}$ \\
\hline Mango & 78.6 & 0.4 & 0.7 & 90 & 1.0 & 0.7 & 20.0 & 16 & 1.3 & 8300 & 0.10 & 0.07 & 41 \\
\hline Jackfruit & 88.0 & 1.1 & 0.2 & 48 & 1.8 & 0.1 & 9.9 & 20 & 0.5 & 4700 & 0.11 & 0.15 & 21 \\
\hline Litchi & 84.1 & 0.5 & 0.5 & 61 & 1.1 & 0.2 & 13.6 & 10 & 0.7 & 0 & 0.02 & 0.06 & 31 \\
\hline Guava & 81.7 & 0.7 & 5.2 & 51 & 0.9 & 0.3 & 11.2 & 10 & 1.4 & 100 & 0.21 & 0.09 & 210 \\
\hline Lime & 84.6 & 0.7 & 1.3 & 59 & 1.5 & 1.0 & 10.9 & 90 & 0.3 & 15 & 0.02 & 0.03 & 63 \\
\hline Ber & 73.2 & 1.0 & - & 104 & 2.9 & 0.1 & 23.8 & 11 & - & 0 & 0.02 & 0.05 & 51 \\
\hline Bel & 77.5 & 0.9 & 2.9 & 87 & 2.6 & 0.2 & 18.8 & 38 & 0.6 & - & 0.03 & 0.02 & 9 \\
\hline Elephant's foot apple & 85.6 & 2.2 & 5.0 & 49 & 3.5 & 0.1 & 8.6 & 59 & 0.6 & 0 & 0.80 & 0.03 & 13 \\
\hline Pummelo & 90.3 & 0.3 & - & 38 & 0.5 & 0.3 & 8.5 & 37 & 0.2 & 120 & 0.06 & 0.04 & 105 \\
\hline Lemon & 88.4 & 0.6 & 1.7 & 47 & 0.3 & 0.7 & 10.0 & 40 & 2.3 & 0 & - & 0.03 & 47 \\
\hline Orange & 89.4 & 0.1 & 0.3 & 43 & 0.7 & 0.1 & 9.7 & 22 & 0.3 & - & 0.04 & 0.01 & 40 \\
\hline Blackberry & 96.6 & 0.1 & 3.8 & 11 & 1.0 & 0.8 & 1.4 & 22 & 4.3 & 120 & 0.01 & 0.024 & 60 \\
\hline $\begin{array}{l}\text { Bullock's heart/ } \\
\text { Custard apple }\end{array}$ & 76.7 & 0.9 & 3.1 & 90 & 1.8 & 0.1 & 20.6 & 17 & 1.5 & 0 & 0.07 & 0.14 & 38 \\
\hline
\end{tabular}

\section{- = not measured.}

\section{Continued....}


Table 1. Continued....

\begin{tabular}{|c|c|c|c|c|c|c|c|c|c|c|c|c|c|}
\hline $\begin{array}{l}\text { Fruits } \\
\text { name }\end{array}$ & $\begin{array}{l}\text { Water } \\
\text { portion } \\
\text { (g) }\end{array}$ & $\begin{array}{l}\text { Total } \\
\text { mineral } \\
\text { (g) }\end{array}$ & $\begin{array}{l}\begin{array}{l}\text { Fiber } \\
\text { (mg) }\end{array} \\
\end{array}$ & $\begin{array}{l}\text { Calorie } \\
\text { (KCal) }\end{array}$ & Protein (g) & $\begin{array}{l}\text { Fat } \\
\text { (g) }\end{array}$ & $\begin{array}{l}\text { Carbohydrate } \\
\text { (g) }\end{array}$ & $\begin{array}{l}\text { Ca } \\
\text { (mg) }\end{array}$ & $\begin{array}{l}\mathrm{Fe} \\
(\mathrm{m} \mathrm{g})\end{array}$ & $\begin{array}{l}\text { Caro-tene } \\
(\mu g)\end{array}$ & $\begin{array}{l}\text { Vita. B-1 } \\
\text { (mg) }\end{array}$ & $\begin{array}{l}\text { Vita.B-2 } \\
\text { (mg) }\end{array}$ & $\begin{array}{l}\text { Vita. } \\
\text { C } \\
\text { (mg) }\end{array}$ \\
\hline Carambola & 88.6 & 0.4 & 1.0 & 50 & 0.5 & 1.0 & 9.5 & 11 & 1.2 & - & 0.12 & 0.04 & 61 \\
\hline Pomegranate & 80.9 & 0.6 & 5.1 & 74 & 1.6 & - & 16.9 & 21 & 0.3 & - & 0.02 & - & 26 \\
\hline Hogplum & 83.2 & 0.6 & 1.0 & 66 & 1.1 & 0.1 & 15 & 55 & 3.9 & 800 & 0.28 & 0.04 & 92 \\
\hline Wax apple & 89.1 & 0.3 & 1.2 & 39 & 0.7 & 0.2 & 8.5 & 10 & 0.5 & 141 & 0.01 & 0.05 & 3 \\
\hline Coconut & 4.3 & 1.6 & 6.6 & 662 & 6.8 & 62.3 & 18.4 & 40 & 2.7 & 0 & 0.08 & 0.01 & 1 \\
\hline Banana & 62.7 & 0.9 & 0.4 & 109 & 0.7 & 0.8 & 25.0 & 13 & 0.9 & 0 & 0.10 & 0.05 & 28 \\
\hline Papaya & 88.4 & 0.7 & 0.8 & 42 & 1.9 & 0.2 & 8.3 & 31 & 0.5 & 8100 & 0.08 & 0.03 & 57 \\
\hline Pineapple & 92.4 & 0.2 & - & 30 & 0.9 & 0.2 & 6.2 & 18 & - & 1830 & 0.11 & 0.04 & 21 \\
\hline Olive & 82.0 & 0.7 & 1.6 & 70 & 1.0 & 0.2 & 16.2 & 22 & 3.1 & - & 0.03 & 0.01 & 39 \\
\hline Aonla & 91.4 & 0.7 & 3.4 & 19 & 0.9 & 0.1 & 3.5 & 34 & 1.2 & 0 & 0.02 & 0.08 & 463 \\
\hline Tamarind & 83.6 & 1.2 & - & 62 & 1.1 & 0.1 & 13.9 & 24 & - & - & 0.01 & 0.02 & 6 \\
\hline Palmyara palm & 77.5 & 0.7 & 0.5 & 87 & 0.7 & 0.2 & 20.7 & 9 & - & - & - & - & - \\
\hline Date palm & 59.2 & 1.7 & 3.7 & 144 & 1.2 & 0.4 & 33.8 & 22 & - & - & - & - & - \\
\hline
\end{tabular}

- = not measured.

Continued.... 
Table 1. Continued....

\begin{tabular}{|c|c|c|c|c|c|c|c|c|c|c|c|c|c|}
\hline $\begin{array}{l}\text { Fruits } \\
\text { name }\end{array}$ & $\begin{array}{c}\text { Water } \\
\text { Portion (g) }\end{array}$ & $\begin{array}{c}\text { Total } \\
\text { minerals } \\
\text { (g) }\end{array}$ & Fiber (mg) & $\begin{array}{l}\text { Calorie } \\
\text { (KCal) }\end{array}$ & Protein (g) & $\begin{array}{l}\text { Fat } \\
\text { (g) }\end{array}$ & $\begin{array}{c}\text { Carbohydrate } \\
\text { (g) }\end{array}$ & Ca (mg) & $\begin{array}{c}\mathrm{Fe} \\
(\mathrm{m} \mathrm{g})\end{array}$ & $\begin{array}{c}\text { Caro-tene } \\
(\mu \mathrm{g})\end{array}$ & $\begin{array}{c}\text { Vita.B-1 } \\
\text { (mg) }\end{array}$ & $\begin{array}{c}\text { Vita.B-2 } \\
\text { (mg) }\end{array}$ & $\begin{array}{c}\text { Vita. C } \\
\text { (mg) }\end{array}$ \\
\hline River ebony & 69.6 & 0.8 & 1.5 & 133 & 1.4 & 0.1 & 26.6 & 58 & - & - & - & - & - \\
\hline Fig & 88.1 & 0.6 & 2.2 & 37 & 1.3 & 0.2 & 7.6 & 80 & 1.1 & 162 & 0.06 & 0.05 & 5 \\
\hline Water chestnut & 84.9 & 0.9 & 0.6 & 65 & 2.5 & 0.9 & 11.7 & 10 & 0.8 & 0 & 0.18 & 0.05 & 15 \\
\hline Burmese grape & - & 0.9 & - & 91 & 1.42 & 0.45 & - & - & 0.3 & - & 0.03 & 0.19 & - \\
\hline Indian dellenia & - & 0.8 & - & 59 & 0.8 & 0.2 & 13.4 & 16 & - & - & - & - & - \\
\hline Velvety apple & 84.9 & 0.2 & 1.5 & 60 & 0.5 & 0.1 & 14.3 & 0.01 & 0.2 & - & - & - & - \\
\hline Monkey jack & - & 0.8 & - & 66 & 0.7 & - & 13.3 & 50 & 0.5 & - & 0.02 & 0.15 & 135 \\
\hline Stargareberry & 91.4 & 0.7 & 3.4 & 19 & 0.9 & 0.1 & 3.5 & 34 & 1.2 & - & 0.02 & 0.08 & 463 \\
\hline Rose apple & - & 0.5 & - & 39 & 0.7 & 0.2 & 23.0 & 10 & 0.5 & 141 & 0.01 & 0.05 & 53 \\
\hline Jamun & 96.6 & 0.1 & 3.8 & 11 & 1.0 & 0.8 & 1.4 & 22 & 4.3 & 120 & 0.09 & 0.02 & 60 \\
\hline Longan & - & - & 0.64 & - & 1.42 & 0.45 & - & - & - & - & - & - & - \\
\hline Plantain & 78.7 & 1.0 & 0.7 & - & 2.6 & 0.4 & 17.3 & 11 & 0.6 & - & 0.09 & 0.06 & - \\
\hline Water melon & 95.8 & 0.3 & 0.2 & 16 & 0.2 & 0.2 & 3.3 & 11 & 7.9 & - & - & 0.04 & 1 \\
\hline
\end{tabular}

- = not measured. 


\section{REFERENCES}

M. K. A. Bhuiyan, 2008. Disease management of vegetables and fruits for poverty alleviation. Proceedings of the $7^{\text {th }}$ Biennial Conference. Bangladesh Phytopathological Society. BARI, Gazipur, P. 33-44.

Annon. 1989. Manual on mango cultivation in Bangladesh. Horticulture Division, Bangladesh Agricultural Research Institute, Gazipur. Pp. 82.

Annon. 2007. Fal Chaser Kola Kousol, Agriculture Information Center, DAE, Khamarbari, Dhaka, Bangladesh. P.69-70.

Annon. 2008. Fal Chaser Kola Kousol, Agriculture Information Center, DAE, Khamarbari, Dhaka, Bangladesh. P.68-69.

S. A. Samson.1980. Tropical fruits. P. 250.

T.K. Bose, S.K. Mitra and M. K. Sadhu. 1988. Mineral nutrition of fruit crops. P. 771.

N. Choudhury. 2009. Food Security and Biotechnology- Global and National Perspectives. Twenty first Bangladesh science conferences, Bangladesh Association for the Advancement of Science. BARI, Gazipur. P. 1-20.

Anon. 2004. Fruit and vegetables for health. Report of a joint FAO/WHO workshop, 1-3 September 2004, Kobe, Japan. 